\title{
Outcome of interventions in elderly persons classified according to the Fried frailty phenotype: an integrative review
}

\section{Abstract}

Objective: To analyze the interventions carried out with elderly persons classified according to the Fried frailty phenotype criteria and the outcomes obtained. Method: The PubMed, Embase, Scopus, CINAHL, PEDro, SciELO, BVS and Web of Science portals were used, and a manual search was applied to identify the interventions implemented in elderly persons aged over 60 years, which were able to modify the scores of the frailty phenotype criteria and other outcomes. Results: The final sample totaled 14 randomized clinical trials published between 2001 and 2018. The combined interventions of exercise, orientation and nutritional supplementation with or without cognitive training presented better outcomes for the frailty criteria and other clinical outcomes in pre-frail and frail elderly persons living in the community and in long-term care facilities. Conclusion: The implementation of combined interventions sustains frailty as a reversible and multifactorial syndrome.
Keywords: Frail Elderly. Frailty. Nutrition. Dietary Supplements. Exercise. Cognition.

Universidade Federal do Pampa, Campus Uruguaiana, Departamento de Enfermagem. Uruguaiana, Rio Grande do Sul, Brasil

2 Universidade Federal do Rio Grande do Sul, Departamento de Enfermagem. Porto Alegre, Rio Grande do Sul, Brasil 


\section{INTRODUCTION}

Frailty in the elderly, which is one of the geriatric syndromes, is widely understood as a decline in biological reserve, resulting in decreased physiological resistance to stressors ${ }^{1}$. According to this definition, frailty may start or be potentiated by the presence of sarcopenia, chronic diseases, malnutrition, a reduced basal metabolism rate and total energy expenditure which, in turn, may be related to senescence and neuroendocrine and immune disorders ${ }^{1,2}$.

One of the most notable of the various definitions and methods for assessing frailty ${ }^{3}$ is the phenotype proposed by Fried et al. ${ }^{1}$, extensively used in clinical practice, due to the fact it can be applied ${ }^{4}$ individually or in combination with other additional criteria ${ }^{5}$. The phenotype consists of five criteria: unintentional weight loss, self-reported exhaustion, weakness (grip strength), slow walking speed and low physical activity ${ }^{1}$. Elderly persons evaluated with one or two criteria are classified as pre-frail and those with three or more of the phenotype criteria are identified as frail ${ }^{1,2,6}$.

The worldwide prevalence of pre-frail and frail elderly persons varies from $34.6 \%$ to $50.9 \%$, and from $5.8 \%$ to $27.3 \%$, respectively ${ }^{7}$. In Brazil, the prevalence of pre-frail elderly is $51.0 \%$ while that of frail elderly is $11.2 \%$, with walking speed and weakness the phenotype criteria with the greatest chance of leading to the development of frailty ${ }^{8}$. This prevalence may increase, as Brazil is expected to occupy sixth place in the world among the countries with the largest number of elderly people by $2025^{9,10}$.

As the presence of one or more frailty phenotype criteria leads to high health costs, early identification of these criteria in the elderly may be clinically useful for health services and professionals seeking the prevention, delay or reversal of frailty ${ }^{11}$.

Evidence suggests that exercise, nutritional support and social support interventions offered by a multiprofessional team can be used to restore and/or maintain functional independence in the elderly and, consequently, prevent or reverse the frailty process ${ }^{3,12,13}$. However, recommendations on the appropriate design of the intervention protocol for each criterion of the frailty phenotype are yet to be presented.

The objective of the present study was to analyze interventions carried out with elderly persons classified using the phenotype criteria of Fried et al. ${ }^{1}$ and the outcomes obtained.

\section{METHOD}

This is an integrative review, which helps identify the best evidence and synthesize it to support proposals for changes in the areas of prevention, diagnosis, treatment and rehabilitation. This research method follows the steps of identification of the problem, a literature search, data evaluation and analysis, and presentation ${ }^{14}$.

To identify the problem, the variables of interest were defined as a proposal, being: frailty conceptualized by Fried et al. ${ }^{1}$; pre-frail elderly persons classified by the presence of one or two frailty phenotype criteria; frail elderly persons classified by the presence of three or more criteria; Intervention characterized by actions that enable outcomes capable of modifying the level of frailty and outcomes as results for the five phenotype criteria and for frailty found following the implementation of the interventions.

Thus, the defined guiding question was: what interventions are carried out with elderly persons classified as pre-frail or frail based on the frailty phenotype criteria, according to Fried et al. ${ }^{1}$, and what outcomes were obtained?

A data search was carried out in September 2018, in the following portals and databases: PubMed, Embase, which includes the Medical Literature Analysis and Retrieval System Online (MEDLINE), the Virtual Health Library (VHL), Cumulative Index to Nursing and Allied Health Literature (CINAHL), Web of Science, Physiotherapy Evidence Database (PEDro), Scientific Electronic Library Online (SciELO) and Scopus.

The selected controlled descriptor frail elderly was used; and uncontrolled descriptors listed to meet 
the five phenotype criteria of Fried et al. (2001), defined as: weakness; slowness; exhaustion; unintentional weight loss and low activity level. In the combination of the descriptors as cited there were no occurrences in SciELO and PEDro, and so the combination weight loss (weight loss AND frail elderly) were used for these two databases.

As the search strategy must be precisely defined and organized, to maintain the scientific nature of all the review formats, Figure 1 presents the six descriptors used in the five search strategies performed in the eight databases.

The present review included randomized controlled trials (RCTs) published from the first definition of the frailty phenotype in the year $2001^{1}$; which classified frailty in individuals aged 60 years or older using the five criteria of the Fried et al. ${ }^{1}$ phenotype in different scenarios; and whose main or secondary objective addressed the change in the frailty level of the elderly persons after the intervention.

To increase the reliability of the information from the databases, a manual search of available articles was conducted, based on the references of the works already collected.

To ensure the selection of publications and data analysis, based on the inclusion and exclusion criteria, an instrument was used with the following information: sample characterization, interventions carried out by the researchers with the sample, results or outcomes achieved by the study, limitations and conclusions. In addition to the variables described above, data associated with the characterization of scientific productions were also collected.

The present study complied with Law $\mathrm{n}^{\circ}$ $9.610 / 98$, intended to preserve and respect the ideas, concepts and definitions of the authors of the analyzed works, which must be presented faithfully, described and cited.

\section{RESULTS}

We identified 6,044 publications in the eight databases and portals analyzed, of which only eight met the inclusion criteria (Figure 2). From these publications, we included six RCTs that were part of the bibliographic references cited by the selected articles. Thus, the final sample of the integrative review (databases, portals and manual search) totaled 14 articles.

Chart 1 provides a summary of the selected articles, highlighting the objective and place of the study. Only two (14.3\%) studies were conducted in an institution for the elderly, one in Amsterdam (Netherlands) $^{15}$ and one in Valencia (Spain) ${ }^{16}$ and, according to the characterization of the articles, $12(85.7 \%)$ studies performed their activities with elderly people living in the community ${ }^{17-28}$. No study carried out in a hospital environment was found.

In Chart 2, we describe the sample of 2,153 prefrail and frail elderly persons (excluding studies from the same research project), of which 1,363 were female. Age ranged from $63^{15}$ to 90 years ${ }^{16}$ with an average of $77.02( \pm 5.19)$ years. 


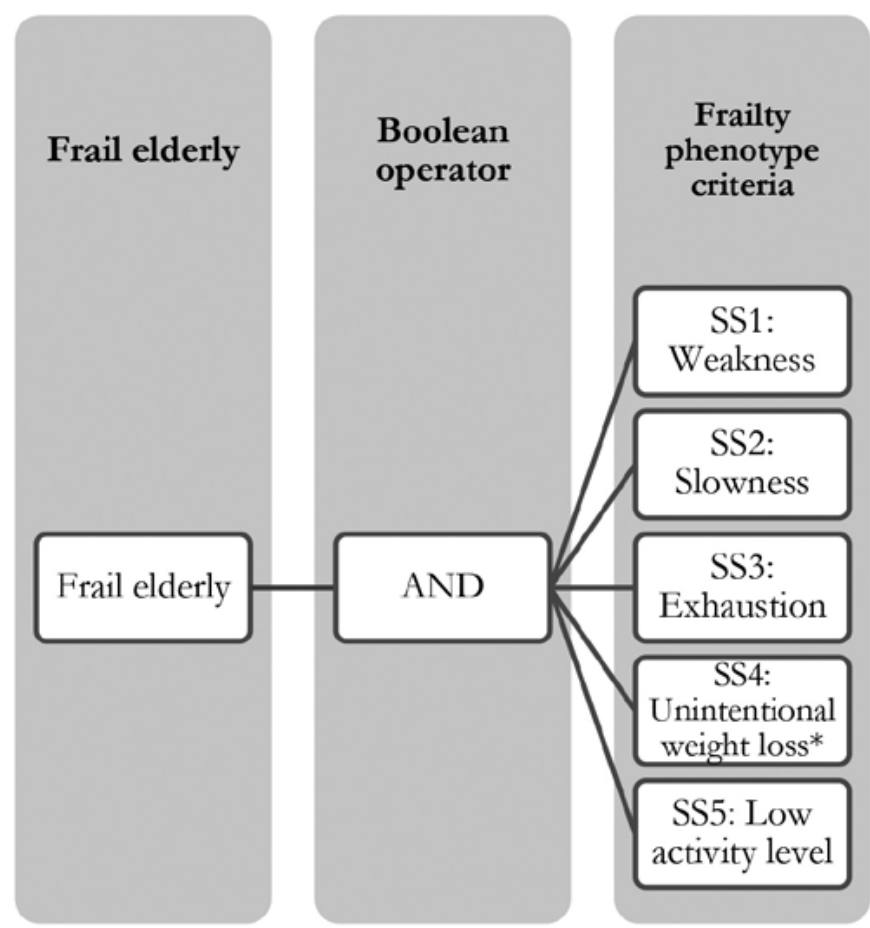

Figure 1. Search strategy using controlled and non-controlled descriptors, 2018.

SS: Search strategy; *Substituted by weight loss in SciELO and PEDro databases

Source: Research data (2018).

\begin{tabular}{|c|c|c|c|c|c|c|c|c|}
\hline \multicolumn{4}{|l|}{ Search Strategy } & \multicolumn{2}{|c|}{$\mathrm{SS} 1+\mathrm{SS} 2+\mathrm{SS} 3+\mathrm{SS} 4+\mathrm{SS} 5$} & \multirow[b]{2}{*}{ Scopus } & \multirow[b]{2}{*}{$\begin{array}{l}\text { Web of } \\
\text { Science }\end{array}$} & \multirow[b]{2}{*}{ Embasc } \\
\hline Databases and portals & BVs & $\begin{array}{l}\text { CINA } \\
\text { HL }\end{array}$ & SciELO & $\begin{array}{c}\text { PubM } \\
\text { ed }\end{array}$ & PEDro & & & \\
\hline Identified & 696 & 567 & 91 & 1.009 & 35 & 2.699 & 798 & 6.468 \\
\hline $\begin{array}{l}\text { Excluded due to falling outside the } \\
\text { theme studied }\end{array}$ & 18 & 151 & 02 & 65 & 07 & 707 & 203 & 72 \\
\hline $\begin{array}{l}\text { Excluded for not considering frailty } \\
\text { classification (Fried et al...) }\end{array}$ & 13 & 28 & 06 & 13 & 15 & 36 & 15 & 17 \\
\hline Excluded due to not using RCT method & 631 & 378 & 66 & 918 & 08 & 1.923 & 571 & 363 \\
\hline $\begin{array}{l}\text { Others (language, date of publication, } \\
\text { scientific article) }\end{array}$ & 07 & 04 & 00 & 07 & 01 & 04 & 00 & 00 \\
\hline Duplicated & 24 & 05 & 17 & 06 & 03 & 29 & 08 & 14 \\
\hline Selected & 03 & 01 & 00 & 00 & 01 & 00 & 01 & 02 \\
\hline Total & & & & 08 & & & & \\
\hline
\end{tabular}

Figure 2. Flowchart of the methodological steps of the integrative review, 2019.

Source: Research data (2018). 
Chart 1. Articles according to author, year, objective and location of randomized clinical trials.

\begin{tabular}{|c|c|c|}
\hline Author, year & Objective & Location of study \\
\hline $\begin{array}{l}\text { Buigues et } \\
\text { al., } 2016^{16}\end{array}$ & $\begin{array}{l}\text { To examine the effectiveness of Darmocare Pre }{ }^{\circledR} \text { biotic formulation } \\
\text { (Bonusan Besloten Vennootschap BV, Numansdorp, the Netherlands) for } \\
\text { improving the frailty syndrome in the elderly. }\end{array}$ & $\begin{array}{l}\text { Valencia Institution } \\
\text { for the Elderly } \\
\text { (Spain) }\end{array}$ \\
\hline $\begin{array}{l}\text { Cameron et } \\
\text { al., } 2013^{17}\end{array}$ & $\begin{array}{l}\text { Determine the effect of intervention on reducing frailty and improving } \\
\text { mobility }\end{array}$ & $\begin{array}{l}\text { Community in } \\
\text { Sydney (Australia) }\end{array}$ \\
\hline $\begin{array}{l}\text { Cameron et } \\
\text { al., } 2015^{18}\end{array}$ & $\begin{array}{l}\text { To examine the effect of a multifactorial, interdisciplinary intervention with } \\
\text { frail elderly persons compared with usual care }\end{array}$ & $\begin{array}{l}\text { Community in } \\
\text { Sydney (Australia) }\end{array}$ \\
\hline $\begin{array}{l}\text { Cesari et al., } \\
2015^{27}\end{array}$ & $\begin{array}{l}\text { To investigate the effects of physical activity on frailty status in a sample of } \\
\text { sedentary elderly at risk of mobility impairment }\end{array}$ & $\begin{array}{l}\text { Community in } \\
\text { Dallas (USA) }\end{array}$ \\
\hline $\begin{array}{l}\text { Chan et al., } \\
2012^{19}\end{array}$ & $\begin{array}{l}\text { Determine whether proposed interventions can have an impact on dynamic } \\
\text { changes in frailty indicators }\end{array}$ & $\begin{array}{l}\text { Community in } \\
\text { Taiwan (China) }\end{array}$ \\
\hline $\begin{array}{l}\text { Chan et al., } \\
2017^{20}\end{array}$ & $\begin{array}{l}\text { To determine the effectiveness of two levels of integrated care on frailty and } \\
\text { sarcopenia }\end{array}$ & $\begin{array}{l}\text { Community in } \\
\text { Taiwan (China) }\end{array}$ \\
\hline $\begin{array}{l}\text { Faber et al., } \\
2006^{15}\end{array}$ & $\begin{array}{l}\text { To determine the effects of a moderate intensity exercise program on falls, } \\
\text { physical performance, and disability in the elderly, and to investigate the } \\
\text { influence of frailty on these effects. }\end{array}$ & $\begin{array}{l}\text { Amsterdam } \\
\text { Institution } \\
\text { for Seniors } \\
\text { (Netherlands) }\end{array}$ \\
\hline $\begin{array}{l}\text { Fairhall et al., } \\
2014^{25}\end{array}$ & $\begin{array}{l}\text { To evaluate the effect of a frailty intervention on risk factors for falls in frail } \\
\text { elderly }\end{array}$ & $\begin{array}{l}\text { Community in } \\
\text { Sydney (Australia) }\end{array}$ \\
\hline $\begin{array}{l}\text { Fairhall et al., } \\
2017^{26}\end{array}$ & $\begin{array}{l}\text { To evaluate the effect of a multifactorial intervention on frailty and mobility } \\
\text { in frail elderly people who complete the allocated treatment }\end{array}$ & $\begin{array}{l}\text { Community in } \\
\text { Sydney (Australia) }\end{array}$ \\
\hline $\begin{array}{l}\text { Kim et al., } \\
2015^{28}\end{array}$ & $\begin{array}{l}\text { To investigate the combined and separate effects of exercise and milk fat } \\
\text { globule membrane supplementation (MFGM) on frailty, physical function, } \\
\text { level of physical activity and hematological parameters in Japanese elderly } \\
\text { women living in the community. }\end{array}$ & $\begin{array}{l}\text { Community in } \\
\text { Tokyo - Japan }\end{array}$ \\
\hline $\begin{array}{l}\text { Li et al., } \\
2010^{24}\end{array}$ & $\begin{array}{l}\text { To evaluate the effectiveness of comprehensive geriatric evaluation and } \\
\text { relevant interventions in pre-frail and frail community-based elderly persons } \\
\text { based on Fried's phenotype criteria and the Barthel Index }\end{array}$ & $\begin{array}{l}\text { Community in } \\
\text { Taiwan - China }\end{array}$ \\
\hline $\begin{array}{l}\text { Ng et al., } \\
2015^{22}\end{array}$ & $\begin{array}{l}\text { To compare the effects of six-month interventions with nutritional } \\
\text { supplementation, physical, cognitive training, and the combined treatment of } \\
\text { these interventions with usual care to reduce frailty in community-dwelling } \\
\text { elderly persons. }\end{array}$ & $\begin{array}{l}\text { Southwest Singapore } \\
\text { Community (Asia) }\end{array}$ \\
\hline $\begin{array}{l}\text { Ng et al., } \\
2017^{23}\end{array}$ & $\begin{array}{l}\text { To investigate the effect of multi-domain lifestyle interventions among frail } \\
\text { and pre-frail elderly persons to reduce symptoms of depression. }\end{array}$ & $\begin{array}{l}\text { Southwest Singapore } \\
\text { Community (Asia) }\end{array}$ \\
\hline $\begin{array}{l}\text { Tarazona- } \\
\text { Santabalbina } \\
\text { et al., } 2016^{21}\end{array}$ & $\begin{array}{l}\text { Verify that a multicomponent exercise program in a supervised facility with } \\
\text { frail elderly persons can reverse frailty and improve functionality; cognitive, } \\
\text { emotional and social networks; as well as biological biomarkers of frailty } \\
\text { when compared to a controlled population that did not receive training }\end{array}$ & $\begin{array}{l}\text { Community in } \\
\text { Valencia (Spain) }\end{array}$ \\
\hline
\end{tabular}


Chart 2. Sample characterization by author, year, age and follow-up of randomized controlled trials.

\begin{tabular}{|c|c|c|c|}
\hline Author, year & Sample, $\%$ of pre, frail and female & $\begin{array}{l}\text { Age [mean and } \\
\text { standard-deviation)] }\end{array}$ & Follow up \\
\hline Buigues et al., $2016^{16}$ & 50 , being $70 \%$ female and $100 \%$ frail & $66-90[73.8( \pm 1.6)]$ & 13 weeks \\
\hline Cameron et al., $2013^{17}$ & 241, being $100 \%$ frail and $68 \%$ female & $>70[83.3( \pm 5.9)]$ & 3-12 months \\
\hline Cameron et al., $2015^{18}$ & 241 , being $100 \%$ frail and $68 \%$ female & $>70[83.3( \pm 5.9)]$ & 12 months \\
\hline Cesari et al., $2015^{27}$ & $\begin{array}{l}424, \text { mean } 1.67( \pm 1.1) \text { frailty criteria and } 68.9 \% \\
\text { female }\end{array}$ & $70-89[76.8( \pm 4.2)]$ & 12 months \\
\hline Chan et al.,2012 & $117,87 \%$ pre-frail, $13 \%$ frail and $59 \%$ female & $65-79[71.4( \pm 3.7)]$ & 12 months \\
\hline Chan et al.,2017 20 & $\begin{array}{l}296 \text { elderly, } 53 \% \text { female, } 21 \% \text { frail and } 79 \% \\
\text { pre-frail }\end{array}$ & $>65[71.6( \pm 4.3)]$ & 6 months \\
\hline Faber et al, $2006^{15}$ & $238,51.1 \%$ pre-frail, $48.9 \%$ frail and $79 \%$ female & $\geq 63[84.9( \pm 6.0)]$ & 52 weeks \\
\hline Fairhall et al., $2014^{25}$ & 241 , being $100 \%$ frail and $67.63 \%$ female & $\geq 70[83.3( \pm 5.9)]$ & 3-12 months \\
\hline Fairhall et al., $2017^{26}$ & 241, being $100 \%$ frail and $67.63 \%$ female & $\geq 70[83.3( \pm 5.9)]$ & 3-12 months \\
\hline Kim et al., $2015^{28}$ & 131, being $100 \%$ frail and female & $\geq 75[80.7( \pm 2.8)]$ & 3 months \\
\hline Li et al., $2010^{24}$ & $\begin{array}{l}310,47.74 \% \text { female, } 18.39 \% \text { frail and } 81.61 \% \\
\text { pre-frail }\end{array}$ & $\begin{array}{l}\geq 65 \text { IG }[78.4( \pm 8.2)] \\
\text { and CG }[79.3( \pm 8.5)]\end{array}$ & 6 months \\
\hline $\mathrm{Ng}$ et al., $2015^{22}$ & $246,51.4 \%$ female, $72 \%$ pre-frail and $28 \%$ frail & $\geq 65[70( \pm 4.7)]$ & 12 months \\
\hline $\mathrm{Ng}$ et al., $2017^{23}$ & $\begin{array}{l}246,51.4 \% \text { female, } 72 \% \text { pre-frail and } 28 \% \text { frail } \\
(28 \%)\end{array}$ & $\geq 65[70( \pm 4.7)]$ & $\begin{array}{l}3,6 \text { and } 12 \\
\text { months }\end{array}$ \\
\hline $\begin{array}{l}\text { Tarazona-Santabalbina } \\
\text { et al., } 2016^{21}\end{array}$ & $100,54 \%$ female and frail $[3.6( \pm 0.8)]$ & $\begin{array}{l}\geq 70 \text { IG }[79.3( \pm 3.6)] \\
\text { and CG }[80.3( \pm 3.7)]\end{array}$ & 12 months \\
\hline
\end{tabular}

The highest prevalence of articles in the sample, which was composed of 14 publications between 2006 and 2017, was found in 2015. This data shows that the search for preventive interventions or treatment of frailty has grown in publications in the area of health and there is currently a clear interest among researchers in identifying the potential of interventions in the assessment of the criteria of the frailty phenotype.

Regarding the structuring of RCTs, interventions that included exercise were identified, both as isolated interventions without association with other types of intervention ${ }^{15}$ and combined with other interventions, such as nutritional orientation or supplementation or cognitive training ${ }^{17-23,25-28}$.

The frequency of exercise sessions ranged from one to five times a week ${ }^{21}$, for 20 minutes at home without supervision ${ }^{19,20}$ to 90 minutes in groups under the supervision of health professionals ${ }^{21}$. The intensity of the exercises oscillated from slow and precise activities, to moderate ${ }^{15}$, graduated and constantly increasing ${ }^{22,28}$ or progressive $\mathrm{e}^{27}$.
Isolated interventions focused on cognitive ${ }^{22,23}$ and nutritional training were identified, whether combined or not with other intervention activities, with the purpose of orienting small groups ${ }^{19,20,27}$, individually orienting the elderly ${ }^{17,18,21,24-26}$, offering supplementation of vitamins and minerals ${ }^{21-23}$, proteins and calories ${ }^{17,18,25,26}$, probiotics ${ }^{16}$ and milk fat globule membrane (MFGM) ${ }^{28}$. The duration of these interventions ranged from 13 weeks $^{16}$ to 12 months ${ }^{17-19,21-23,25-27}$.

The combined interventions were exercise with problem-solving therapy or psychotherapy, nutritional counseling and/or supplementation ${ }^{19,20}$, cognitive training ${ }^{21-23,28}$, based on a supervised multidisciplinary and interdisciplinary program ${ }^{17,18,25,26}$ and interdisciplinary interventions coordinated by geriatricians $^{24}$.

According to the RCT results, one or more criteria of the frailty phenotype (unintentional weight loss, self-reported exhaustion, weakness (grip strength), reduced walking speed and low physical activity) and other non-frailty phenotype variables 
were modified after the implementation of single or combined interventions in pre-frail or non-frail elderly persons.

Among the sample studies, five (35.7\%) articles resulted in the modification of the grip strength weakness phenotype criterion after the interventions ${ }^{16,19,20,22,25,26}$. Modification of the reduced walking speed frailty phenotype criterion was identified in eight $(57.1 \%)$ publications, with the best results obtained in the periods of 13 weeks ${ }^{16}$ and 12 months $s^{17,18,21,22,25}$.

The self-reported exhaustion frailty phenotype criterion was modified in three $(21.43 \%)$ publications ${ }^{16,20,28}$. The intervention that associated exercise with vitamin and mineral supplementation not only reversed exhaustion within three months (post-intervention), but also obtained a higher odds ratio for the reversal of frailty in the post-intervention and follow-up ${ }^{28}$ period than the other groups.

Only four $(28.57 \%)$ publications modified the unintentional weight loss criterion after the interventions $s^{19,21,22,28}$. Among these were isolated exercise programs that aimed to improve strength and balance, the oral intake of vitamin and mineral supplements, and cognitive training after 12 months. Other interventions combined exercise with nutritional guidance, problem-solving therapy ${ }^{19,21}$, cognitive training ${ }^{22}$ and nutritional supplementation ${ }^{28}$.

Low physical activity was modified in five (35.7\%) publications, and two (14.28\%) reversed physical inactivity through exercise over 12 months $^{27}$, and the ingestion of nutritional supplementation for six and 12 months $^{22}$. The other interventions were exercise combined with supplements ${ }^{28}$, orientation ${ }^{20}$ and nutritional supplementation ${ }^{21}$.

The implementation of interventions among the pre-frail and frail elderly was able to modify other variables that are not part of the five phenotype criteria that classify frailty in the elderly ${ }^{15-17,19,21,23-25}$. The intervention that obtained the highest number of modified variables after undergoing interventions was combined exercise, orientation and nutritional supplementation ${ }^{21}$.

The interventions that modified the five criteria of the frailty phenotype and the other variables are listed in Table 3 below.

Chart 3. Criteria of the frailty phenotype and other variables that changed frailty and its outcomes after single or combined interventions.

\begin{tabular}{|c|c|c|}
\hline Outcome & Interventions & Author, year \\
\hline \multirow[t]{5}{*}{ Increased muscle strength } & Ex. + NuOri + ProTh & Chan et al., $2012^{19}$ \\
\hline & $\begin{array}{l}\text { Ex. }+ \text { NuOri }+ \text { ProTh }+ \text { HoCa } \\
\text { Ex. }+ \text { NuOri }+ \text { ProTh }\end{array}$ & Chan et al., $2017^{20}$ \\
\hline & $\begin{array}{l}\text { Ex. } \\
\text { CogTra } \\
\text { Ex. +CogTra }+ \text { VMNu }\end{array}$ & $\mathrm{Ng}$ et al., $2015^{22}$ \\
\hline & MuProg. & Fairhall et al., $2014^{25}$ \\
\hline & Probiotic nutritional supplementation & Buigues et al., 2016 16 \\
\hline
\end{tabular}


Continuation of Chart 3

\begin{tabular}{|c|c|c|}
\hline Outcome & Interventions & Author, year \\
\hline \multirow[t]{5}{*}{ Increased gaitspeed } & $\begin{array}{l}\text { Ex. }+ \text { NuOri }+ \text { Pro'Th }+ \text { HoCa } \\
\text { Ex. }+ \text { NuOri }+ \text { Pro'Th }+ \text { Su }\end{array}$ & Chan et al., $2017^{20}$ \\
\hline & $\begin{array}{l}\text { Ex. } \\
\text { VMNu } \\
\text { CogTra } \\
\text { Ex. +CogTra + VMNu }\end{array}$ & $\begin{array}{l}\mathrm{Ng} \text { et al., } 2015^{22} \\
\mathrm{Ng} \text { et al., } 2017^{23}\end{array}$ \\
\hline & MuProg. & $\begin{array}{l}\text { Fairhall et al., } 2014^{25} \\
\text { Cameron et al., } 2015^{18} \\
\text { Cameron et al., } 2013^{17}\end{array}$ \\
\hline & Probiotic nutritional supplementation & Buigues et al., $2016^{16}$ \\
\hline & $\begin{array}{l}\text { Ex. } \\
\text { MfgmNu } \\
\text { Ex. }+ \text { MfgmNu }\end{array}$ & Kim et al., $2015^{28}$ \\
\hline \multirow[t]{5}{*}{ Increased body weight } & Ex. + NuOri + ProTh & Chan et al., $2012^{19}$ \\
\hline & $\begin{array}{l}\text { Ex. } \\
\text { VMNu } \\
\text { Cognitive training } \\
\text { Ex. +CogTra + VMNu }\end{array}$ & Ng et al., $2015^{22}$ \\
\hline & Ex. + MfgmNu & Kim et al., $2015^{28}$ \\
\hline & Ex. + NuOri + VMNu & Tarazona-Santabalbina et al., $2016^{21}$ \\
\hline & OriBGE & Li et al. $2010^{24}$ \\
\hline \multirow{3}{*}{$\begin{array}{l}\text { Improvement in self-reported } \\
\text { exhaustion }\end{array}$} & Probiotic nutritional supplementation & Buigues et al., $2016^{16}$ \\
\hline & $\begin{array}{l}\text { Ex. } \\
\text { MfgmNu } \\
\text { Ex. + MfgmNu }\end{array}$ & Kim et al., $2015^{28}$ \\
\hline & $\begin{array}{l}\text { Ex. + NuOri }+ \text { ProTh }+ \text { HoCa } \\
\text { Ex. }+ \text { NuOri }+ \text { ProTh }\end{array}$ & Chan et al., $2017^{20}$ \\
\hline \multirow[t]{5}{*}{ Increased physical activity } & $\begin{array}{l}\text { Ex. + NuOri }+ \text { ProTh }+\mathrm{HoCa} \\
\text { Ex. }+ \text { NuOri }+ \text { ProTh }+\mathrm{Su}\end{array}$ & Chan et al., $2017^{20}$ \\
\hline & $\mathrm{VMNu}$ & $\mathrm{Ng}$ et al., $2015^{22}$ \\
\hline & Ex. + MfgmNu & Kim et al., $2015^{28}$ \\
\hline & Ex. + NuOri + VMNu & Tarazona-Santabalbina et al., $2016^{21}$ \\
\hline & Ex. & Cesari et al., $2015^{27}$ \\
\hline ADL and IADL dependence & Ex. + NuOri + VMNu & Tarazona-Santabalbina et al., $2016^{21}$ \\
\hline Health care & Ex. + NuOri + VMNu & Tarazona-Santabalbina et al., $2016^{21}$ \\
\hline Osteopenia & Ex. + NuOri + ProTh & Chan et al., $2012^{19}$ \\
\hline Vitamin D & Ex. + NuOri + ProTh & Chan et al., $2012^{19}$ \\
\hline 25-Hydroxyvitamin D Level & Ex. + NuOri + ProTh & Chan et al., $2012^{19}$ \\
\hline \multirow[t]{3}{*}{ Falls } & MuProg & Fairhall et al., $2014^{25}$ \\
\hline & Ex. + NuOri + VMNu & Tarazona-Santabalbina et al., $2016^{21}$ \\
\hline & Exercise & Faber et al., $2006^{15}$ \\
\hline \multirow[t]{2}{*}{ Balance } & MuProg. & Fairhall et al., $2014^{25}$ \\
\hline & Ex. & Faber et al., $2006^{15}$ \\
\hline
\end{tabular}


Continuation of Chart 3

\begin{tabular}{|c|c|c|}
\hline Outcome & Interventions & Author, year \\
\hline \multirow[t]{3}{*}{ Physical performance } & MuProg. & $\begin{array}{l}\text { Fairhall et al., } 2014^{25} \\
\text { Cameron et al., } 2013^{17}\end{array}$ \\
\hline & Ex. + NuOri + VMNu & Tarazona-Santabalbina et al., $2016^{21}$ \\
\hline & Ex. & Faber et al., $2006^{15}$ \\
\hline \multirow[t]{2}{*}{ Functional state } & Probiotic nutritional supplementation & Buigues et al., $2016^{16}$ \\
\hline & Ex. & Faber et al., $2006^{15}$ \\
\hline Sleep quality & Probiotic nutritional supplementation & Buigues et al., $2016^{16}$ \\
\hline \multirow[t]{2}{*}{ Mental state } & Probiotic nutritional supplementation & Buigues et al., $2016^{16}$ \\
\hline & Ex. $+\mathrm{NuOri}+\mathrm{VMNu}$ & Tarazona-Santabalbina et al., $2016^{21}$ \\
\hline Social support & Ex. + NuOri + VMNu & Tarazona-Santabalbina et al., $2016^{21}$ \\
\hline \multirow[t]{2}{*}{ Depression } & Ex. + NuOri + VMNu & Tarazona-Santabalbina et al., $2016^{21}$ \\
\hline & $\begin{array}{l}\text { Ex. } \\
\text { VMNu } \\
\text { Ex. +CogTra + VMNu }\end{array}$ & $\mathrm{Ng}$ et al., $2017^{23}$ \\
\hline Quality of life & Ex. + NuOri + VMNu & Tarazona-Santabalbina et al., $2016^{21}$ \\
\hline Calcium level & Ex. + NuOri + VMNu & Tarazona-Santabalbina et al., $2016^{21}$ \\
\hline Blood clotting & Ex. + NuOri + VMNu & Tarazona-Santabalbina et al., $2016^{21}$ \\
\hline Physical rehabilitation & OriBGE & Li et al. $2010^{24}$ \\
\hline Geriatric evaluation & OriBGE & Li et al. $2010^{24}$ \\
\hline Referrals to specialists & OriBGE & Li et al. $2010^{24}$ \\
\hline Polypharmacy & OriBGE & Li et al. $2010^{24}$ \\
\hline Mobility & Ex. & Faber et al., $2006^{15}$ \\
\hline
\end{tabular}

Ex.: Exercise; NuOri: nutritional orientation; ProTh: problem solving therapy; HoCa: home care; CogTra.: cognitive training; VMNu: vitamins and minerals nutritional supplementation; MfgmNu: milk fat globule membrane nutritional supplementation; OriBGE: orientations based on broad geriatric evaluation; ADL: activities of daily living; iADL: instrumental activities of daily living; MuProg., interdisciplinary and individual multifactorial program; Su.: supervised by professionals.

\section{DISCUSSION}

The analysis of the articles allowed the guiding question of the study to be answered and from this, the definition of frailty as a reversible syndrome to be corroborated. Systematic reviews reinforce the finding that physical activity ${ }^{4,29}$ combined with other interventions may minimize or delay the onset of frailty among the elderly because its effects can influence other variables that, in turn, influence the aging process and enhance the outcomes of frailty ${ }^{11,29}$.

The particularity of the RCTs, which consider only frail elderly persons in their sample and in which more than half of those sampled were women over 80 years of age 15-18,21,25,26,28 , provides greater precision and confidence regarding the effectiveness of interventions, as these inherent characteristics of the sample potentiate consequences of frailty $y^{30,31}$.
Among the frailty phenotype criteria, self-reported exhaustion was the criterion in which the outcome changed the least following the interventions. It can be supposed that the subjectivity involved in measuring exhaustion means that it cannot be guaranteed that the interventions are best suited to modifying this criterion. The modification of exhaustion is not dependent on cognitive or psychological aspects, but on professionals who are willing to supervise the elderly during exercises and manage their food intake by offering supplementation. This deduction is confirmed when the elderly person is referred to the psychiatrist or psychologist for the treatment of depressive symptoms and exhaustion, without changes in the self-reported exhaustion criterion ${ }^{17,18,25,26}$.

Weakness in grip, as measured by handgrip strength, presented the best outcome for the combined interventions of exercise, orientation 
and nutritional supplementation, as found in the literature ${ }^{5,32,33}$. Two groups of researchers ${ }^{19,20}$ obtained improvements in the criterion by including, in addition to exercise and nutritional orientation, problem-solving therapy activities. The identification of interventions that significantly modify this criterion is extremely important because, as well as classifying frailty, it is a predictive method for mortality and disability ${ }^{34}$.

The modification of the reduced walking speed frailty phenotype criterion, identified in $17.84 \%$ of the elderly resident in the community ${ }^{31}$, is relevant in the context of health, as it is a predictive measure for several negative outcomes since it is related to the use of the sensory, motor and structural organs when traveling four meters at a speed less than 0.8 meters/second ${ }^{31,35}$. The integration and functionality of the physiological system required to increase walking speed in the elderly became more effective through monitoring and encouraging the elderly to begin and continue physical activity at home ${ }^{17,18,22,25}$ and consume a high calorie intake, with or without supplementation ${ }^{17,22,28}$.

The low physical activity frailty phenotype criterion presented better results following a combined exercise, orientation and nutritional supplementation intervention ${ }^{21}$ than with the other interventions. This combined intervention reduced physical inactivity, increased walking time to more than three hours per week, and modified psychosocial, biochemical status and adverse health consequences $^{21}$. In other words, the sensitivity for modifying low physical activity and frailty is direct, but not proportional, since inactivity does not necessarily reverse frailty.

The criterion of the unintentional weight loss frailty phenotype, identified in $57.7 \%$ of frail elderly persons ${ }^{36}$, may have been triggered by neuroendocrine and musculoskeletal disorders, malnutrition, inflammation, catabolic diseases and decreased muscle mass ${ }^{1}$. However, it can be inferred that the lack of social support associated with the functional limitations of the elderly may be the cause of low nutritional intake, since the change in the score for the weight loss criterion was due to the preparation and provision of meals at the home of the elderly person ${ }^{19,28}$.

However, the diversity of interventions cannot guarantee the existence of an ideal action that will reverse the criterion of the unintentional weight loss frailty phenotype in the long term, as the outcomes differ due to the scale of the effects. It was found, however, that the unintentional weight loss, grip strength and low physical activity criteria can be affected by many interventions and may undergo modifications following non-specific interventions.

Although the assessment instrument for frailty includes only physiological criteria ${ }^{1}$, it is possible to state that interventions focused on pre-frail and frail elderly persons modify other variables that include the social, emotional, environmental, behavioral, cognitive, functional and physiological domains. This finding demonstrates that frailty, even when evaluated by physiological parameters, can be influenced by the modification of other variables, such as balance, falls, dependence in daily and instrumental activities of living, social support, sleep quality, mental state and quality of life, which potentiate the consequences of frailty.

The significant number of outcomes for the combined interventions lead to findings that frailty is sensitive to resistance, strength, balance and sensory perception exercises, general guidance, and nutritional supplementation. In addition, the effect of the interventions increased when the proposed activities provided socialization in small groups of elderly persons. However, this does not mean that isolated interventions do not have beneficial outcomes for the elderly, as compared to combined interventions they tend to increase the effect of the outcomes, making them less effective and comprehensive for the health of the elderly, whether pre-frail or frail.

As this study exclusively included RCTs that classified their sample based on the Fried et al. ${ }^{1}$ frailty phenotype, there was an absence of bias regarding the inclusion of only the pre-frail and frail elderly. Possible limitations in the results presented in this study are based on the fact that it was restricted to certain data searches and languages and the inclusion 
only of the elderly classified from the Fried et al. ${ }^{1}$ frailty phenotype, with the exclusion of references that conceptualize frailty as a multidimensional clinical condition. The objective and explicit operationalization of the frailty phenotype $\mathrm{e}^{13}$ is valid and widely used in scientific evidence ${ }^{37}$, ensuring predictive validity to identify the signs, symptoms and risk factors or determinants of frailty ${ }^{11}$.

Although this review has applied well-defined inclusion criteria and adopted the integrative review method, no interventions developed with hospitalized elderly persons involving family or caregivers of pre-frail and frail elderly persons during activities were identified. It can be conjectured that adherence to interventions may present greater ease and participation with family support in any health context, which would impact comprehensive and effective outcomes for the elderly, their families and society.

\section{REFERENCES}

1. Fried LP, Tangen CM, Walston J, Newman AB, Hirsch C, Gottdiener J, et al. Frailty in older adults: evidence for a phenotype. J Gerontol Ser A Biol Sci Med Sci. 2001;56(3)146-56.

2. Fried LP, Ferrucci L, Darer J, Williamson JD, Anderson G. Untangling the concepts of disability, frailty, and comorbidity: implications for improved targeting and care. J Gerontol Ser A Biol Sci Med Sci. 2004;59(3):255-63.

3. Frost RF, Belk C, Jovicic A, Ricciardi F, Kharicha K, Gardner B, et al. Health promotion interventions for community-dwelling older people with mild or prefrailty: a systematic review and meta-analysis. BMC Geriatr. 2017;17:1-13.

4. de Labra C, Guimaraes-Pinheiro C, Maseda A, Lorenzo T, Millán-Calenti JC. Effects of physical exercise interventions in frail older adults: a systematic review of randomized controlled trials. BMC Geriatr. 2015;15(1):1-16.

5. Dedeyne L, Deschodt M, Verschueren S, Tournoy J, Gielen E. Effects of multi-domain interventions in (pre) frail elderly on frailty, functional, and cognitive status: a systematic review. Clin Interv Aging. 2017;12:873-96.

6. Walston J, Buta B, Xue QL. Frailty Screening and Interventions: Considerations for Clinical Practice. Clin Geriatr Med. 2018;34(1):25-38

\section{CONCLUSION}

The results of this review corroborate frailty as a reversible syndrome, as the outcome of interventions is effective in modifying the Fried et al. ${ }^{1}$ phenotype criteria and, consequently, in reducing frailty levels among the elderly. However, replicating interventions that have brought benefits to the elderly may require adaptations or adjustments, due to the differences in the policy, health and professional structure available for the care of the elderly in Brazil.

Modification of other variables in addition to the phenotype criteria following the interventions reinforces that frailty is multifactorial and can sometimes be a risk factor or consequence for other health complications. It is believed that the modification of these other variables will give a broader view of the elderly, aimed not only at frailty, but also to the biopsychosocial process of aging.

7. Collard RM, Boter H, Schoevers RA, Oude Voshaar RC. Prevalence of frailty in community-dwelling older persons: a systematic review. J Am Geriatr Soc. 2012;60(8):1487-92.

8. Silva SL, Neri AL, Ferrioli E, Lourenço RA, Dias RC. Fenótipo de fragilidade: influência de cada item na determinação da fragilidade em idosos comunitários Rede Fibra. Ciênc Saúde Colet. 2016;21(11):3483-92.

9. Sesso RC, Lopes AA, Thomé FS, Lugon JR, Martins CT. Inquérito Brasileiro de Diálise Crônica. J Bras Nefrol [Internet]. 2017 [acesso em 19 mar. 2018];39(3):261-6. Disponível em: http://www.scielo. br/pdf/jbn/v39n3/pt_0101-2800-jbn-39-03-0261.pdf

10. Instituto Brasileiro de Geografia e Estatística. Síntese de indicadores sociais: uma análise das condições de vida da população brasileira. Estudos e pesquisas: Informação demográfica e socioeconômica [Internet]. 2010 [acesso em 01 mar. 2018]. Disponível em: http:// www.ibge.gov.br

11. Puts MT, Toubasi S, Andrew MK, Ashe MC, Ploeg $\mathrm{J}$, Atkinson E, et al. Interventions to prevent or reduce the level of frailty in community-dwelling older adults: a scoping review of the literature and international policies. Age Ageing. 2017;46:383-92. 
12. Behm L, Eklund K, Wilhelmson K, Zide L, Gustafsson S, FalkK, et al. Health promotion can postpone frailty: results fromthe RCT elderly persons in the Risk Zone. Public Health Nurs. 2016;33(4):303-15.

13. Serra-Prat M, Sist X, Domenich R, Jurado L, Saiz A, Roces A, et al. Effectiveness of an intervention to prevent frailty in pre-frail community-dwelling older people consulting in primary care: a randomised controlled trial. Age Ageing. 2017;46:401-7.

14. Whittemore R, Knafl K. The integrative review: updated methodology. J Adv Nurs. 2005;52(5):546-53.

15. Faber MJ, Bosscher RJ, Paw MJCA, van Wieringen PC. Effects of exercise programs on falls and mobility in frail and pre-frail older adults: a multicenter randomized controlled trial. Arch Physi Med Rehabil. 2006;87(7):885-96.

16. Buigues C, Fernandez-Garrido J, Pruimboom L, Hoogland A, Navarro-Martínez R, MartÍnezMartínez M, et al. Effect of a prebiotic formulation on frailty syndrome: a randomized, double-Blind clinical trial. Int J Mol Sci. 2016;17(6):1-12.

17. Cameron ID, Fairhall N, Langron C, Lockwood K, Monaghan N, et al. A multifactorial interdisciplinary intervention reduces frailty in older people: randomized trial. BMC Geriatr. 2013;11:1-10.

18. Cameron ID, Fairhall N, Gill L, Lockwood C, Aggar C, Monaghan N, et al. Developing interventions for frailty. Adv Geriatr. 2015;2015:1-7.

19. Chan DC, Tsou HH, Yang RS, Chen CY, Hsiung CA, Kuo KN. A pilot randomized controlled trial to improve geriatric frailty. BMC Geriatr. 2012;12:1-12

20. Chan DD, Tsou HH, Chang CB, Yang RS, Tasauo $\mathrm{JY}$, et al. Integrated care for geriatric frailty and sarcopenia: a randomized control trial. J Cachexia Sarcopenia Muscle. 2017;8(1):78-88.

21. Tarazona-Santabalbina F, Gomez-Cabrera M, Perez-Ros P, Martínez-Arnau F, Tsaparas K, et al. A multicomponent exercise intervention that reverses frailty and improves cognition, emotion, and social networking in the community-dwelling frail elderly: a randomized clinical trial. J Am Med Dir Assoc. 2016;17(5):426-33.

22. Ng TP, Nyunt MSZ, Feng L, Feng M, et al. Multidomains lifestyle interventions reduces depressive symptoms among frail and pre-frail older persons: randomized controlled trial. J Nutr Health Aging. 2017;21(8):918-26.

23. Ng TP, Feng L, Nyunt MS, et al. Nutritional, physical, cognitive, and combination interventions and frailty reversal among older adults: a randomized controlled trial. Am J Med. 2015;128(11):1225-36.
24. Li CM, Chen CY, Li CY, Wang WD, Wu SC. The effectiveness of a comprehensive geriatric assessment intervention program for frailty in communitydwelling older people: a randomized, controlled trial. Arch Gerontol Geriatr. 2010;50(suppl 1):39-42.

25. Fairhall N, Sherrington C, Lord SR, Kurrle SE, Langron C, Lockwood K, et al. Effect of a multifactorial, interdisciplinary intervention on risk factors for falls and fall rate in frail older people: a randomised controlled trial. Age Ageing. 2014;43(5):616-22.

26. Fairhall N, Sherrington C, Cameron ID, et al. A multifactorial intervention for frail older people is more than twice as effective among those who are compliant: complier average causal effect analysis of a randomized trial. J Physiother. 2017;63(1):40-4.

27. Cesari M, Vellas B, Hsu FC, Newman AB, Doss H, King AC, et al. A physical activity intervention to treat the frailty syndrome in older persons: results from the LIFE-P study. J Gerontol Ser A Biol Sci Med Sci. 2015;70(2):216-22.

28. Kim H, Suzuki T, Kim M, Kojima N, Ota N, Shimotoyodone A, et al. Effects of exercise and milk fat globule membrane (MFGM) supplementation on body composition, physical function, and hematological parameters in community-dwelling frail Japanese women: a randomized double blind, placebo-controlled, follow-up trial. PLoS ONE. 2015;10(2):1-20.

29. Chou CH, Hwang CL, Wu YT. Effect of exercise on physical function, daily living activities, and quality of life in the frail older adults: a meta-analysis. Arch Phys Med Rehabil. 2012;93(2):237-44.

30. Crossetti MGO, Antunes M, Waldman BF, Unicovsky MAR, de Rosso LH, Lana LD. Fatores que contribuem para o diagnóstico de enfermagem risco para a síndrome do idoso frágil. Rev Gaúch Enferm. 2018;39: e2017-0233 [9p.].

31. Gross CB, Kolankiewicz ACB, Schmidt CR, Berlezi EM. Níveis de fragilidade de idosos e sua associação com as características sociodemográficas. Acta Paul. Enferm. 2018;31(2):209-16.

32. Giné-Garriga M, Guerra M, Unnithan VB. The effect of functional circuit training on self-reported fear of falling and health status in a group of physically frail older individuals: a randomized controlled trial. Aging Clin Exp Res. 2013;25(3):329-36.

33. Lozano-Montoya I, Correa-Pérez A, Abraha I, Soiza RL, Cherubini A, O’Mahony D, et al. Nonpharmacological interventions to treat physical frailty and sarcopenia in older patients: a systematic overview: the SENATOR Project ONTOP Series. Clin Interv Aging. 2017;12:721-40. 
34. Lenardt MH, Binotto MA, Carneiro NHK, Cechinel C, Betiolli SE, Lourenço TM. Handgrip strength and physical activity in frail elderly. Rev Esc Enferm USP. 2016;50(1):86-92.

35. Moreira VG, Lourenço RA. Prevalence and factors associated with frailty in an older population from the city of Rio de Janeiro, Brazil: the FIBRA-RJ Study. Clinics. 2013;68(7):979-85.
36. Julio MPM, Clavero AE, Soler MLM. Nutritional status and factors associated with noninstitutionalized people over 75 years of age. Rev Bras Enferm. 2018;71:1007-12.

37. Buta BJ, Walston JD, Godino JG, Park M, Kalyani RR, Xue QL, et al. Frailty assessment instruments: systematic characterization of the uses and contexts of highly-cited instruments. Ageing Res Rev. 2016;26:53-61. 